\title{
The Determination of Armhole Curve of Similar Pattern for Margin Structure and Its Sleeves Arrangement
}

\author{
Jing An \\ Arts and Design School \\ Huanghe Science and Technology College \\ Zhengzhou, Henan, 450000
}

\begin{abstract}
It is difficult to precisely control the armhole curve and sleeve cap curve in the design of similar pattern for margin structure. In this paper, with men's clothing prototype for example and with the pattern of chest circumference $94 \mathrm{~cm}$ and margin $10 \mathrm{~cm}$ as the center, take the maximum and minimum limit values of chest circumference and margin to make verification, so as to find the proportional relations when the armhole curve and sleeve cap curve tracing points are determined, and further to simplify and standardize the pattern rendering procedure of similar pattern for margin, and to provide an expert knowledge platform for the development of PDS intelligent systems of computer in the future.
\end{abstract}

Keywords—similar pattern for margin; armhole curve; tracing point; sleeves arrangement

\section{INTRODUCTION}

In the pattern design process of men's clothing, when we make transition from the basic pattern to the basic sub-pattern, it will inevitably involve the issues of scaling according to the model required for clothing. Here the "scaling" does not mean the concept of pusher plate, but the scaling on the basis of relaxation, so as to form a new basic sub-pattern, e.g. the basic pattern of a coat is produced in this way. Depending on the different structural type of garment, the pattern adjustment has two ways of similar pattern margin and variant pattern margin. This paper made a discussion mainly on the determination of armhole curve and sleeve cap curve in the similar pattern for margin structure.

The similar pattern margin is mainly used for fitted garments, such as coat, which requires the wearer wears inner shirt, vest and suit (mainly referring to the business suit). The comparable state is formed between coat and inner, ie the dimensionality and length of coat should be increased proportionally with respect to the inner, and only when increased in geometric proportion, the relations between inner and outer clothing can keep "unisonous", so as to make the wearer feel comfortable. The similar patterns were rendered by experiences of people before, without standard rendering methods, especially the determination of armhole curve and sleeve cap curve, thus errors may be caused easily, not conducive to progress and improvement of pattern technology. In this paper, by the method of expansion at geometric proportion of geometric series and with the pattern of chest circumference $94 \mathrm{~cm}$ and margin $10 \mathrm{~cm}$ as the center, take the two limit values of chest circumference and margin to verify the proportional relations when the armhole curve and sleeve cap curve tracing points are determined, so as to improve the standardization and efficiency of pattern, and further to provide an expert knowledge platform for the development of PDS intelligent systems of computer in the future.

\section{THE EXPERIMENT TO DETERMINE THE ARMHOLE CURVE OF SIMILAR PATTERN FOR MARGIN}

A. The experimental methods to determine the armhole curve of similar pattern for margin

In the study, complete the similar pattern of chest circumference $94 \mathrm{~cm}$ and margin $10 \mathrm{~cm}$ by experiences, with geometric series of $2: 1.5: 1: 0.5$, and analyze the data results to get the formula of proportion for determining the tracing points, and then by this formula and with the pattern of chest circumference $94 \mathrm{~cm}$ and margin $10 \mathrm{~cm}$ as the center, respectively find the limits in four directions. If the tracing points we find in case of the limits, can still constitute correct armhole curve, it can be ensured in its coverage that the determination of tracing points of armhole curve is correct (Fig. $1)$. 


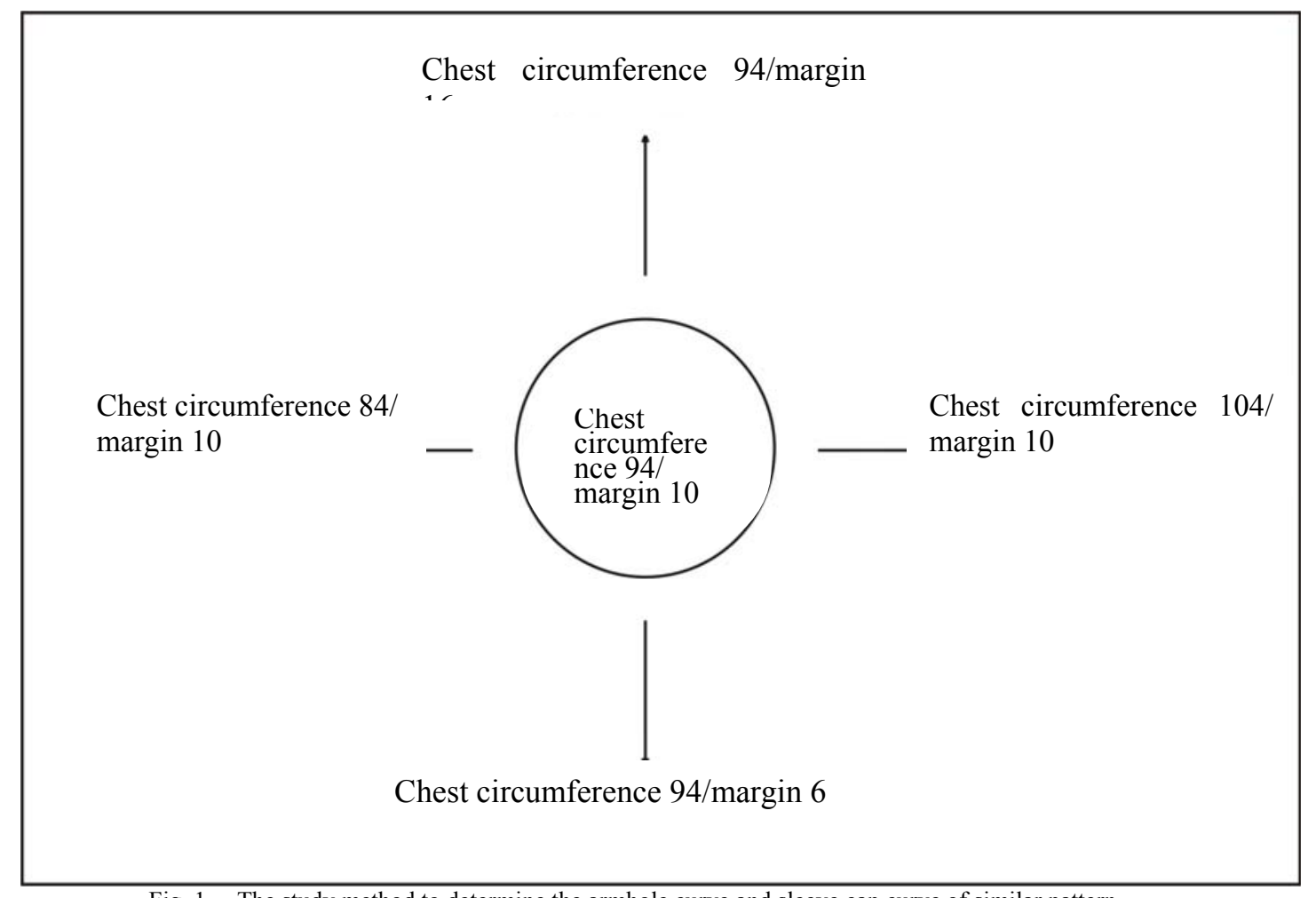

Fig. 1. The study method to determine the armhole curve and sleeve cap curve of similar pattern

\section{B. The experimental procedures to determine the armhole curve of similar pattern}

To draft the similar pattern ( Fig.2 ) of chest circumference $94 \mathrm{~cm}$ and margin $10 \mathrm{~cm}$ by experiences, with geometric series of $2: 1.5: 1: 0.5$, first complete the basic pattern of chest circumference $94 \mathrm{~cm}$ in specification according to the prototype pattern drafting method; secondly, complete the basic sub-pattern of similar pattern for margin structure on the basis of the basic pattern: (1) allocate the margin of $10 \mathrm{~cm}$ in accordance with the geometric series of $2: 1.5: 1: 0.5$, with half of $5 \mathrm{~cm}$, i.e., the rear side seam is $2 \mathrm{~cm}$, fore side seam is $1.5 \mathrm{~cm}$, rear center seam is $1 \mathrm{~cm}$, fore center seam is $0.5 \mathrm{~cm}$. (2) the elevation of shoulder part is the sum of fore and rear center seams, that of back piece higher than that of fore piece, that is, back shoulder part elevated $1 \mathrm{~cm}$ and fore shoulder part elevated $0.5 \mathrm{~cm}$. (3) the elevation of back-neck part is half of that of rear shoulder part, that is $0.5 \mathrm{~cm}$. (4) the stretch of shoulder part is half of the sum of the fore, middle and rear margins, that is $0.8 \mathrm{~cm}$. (5) the open depth of armhole part is the side seam margin minus half of the elevation of shoulder part, that is $2.8 \mathrm{~cm}$. (6) the down adjustment of waist line is approximately half of open depth of armhole part, that is $1.4 \mathrm{~cm}$. Finalize the basic sub-pattern according to the principles of armhole curvatures being similar. 


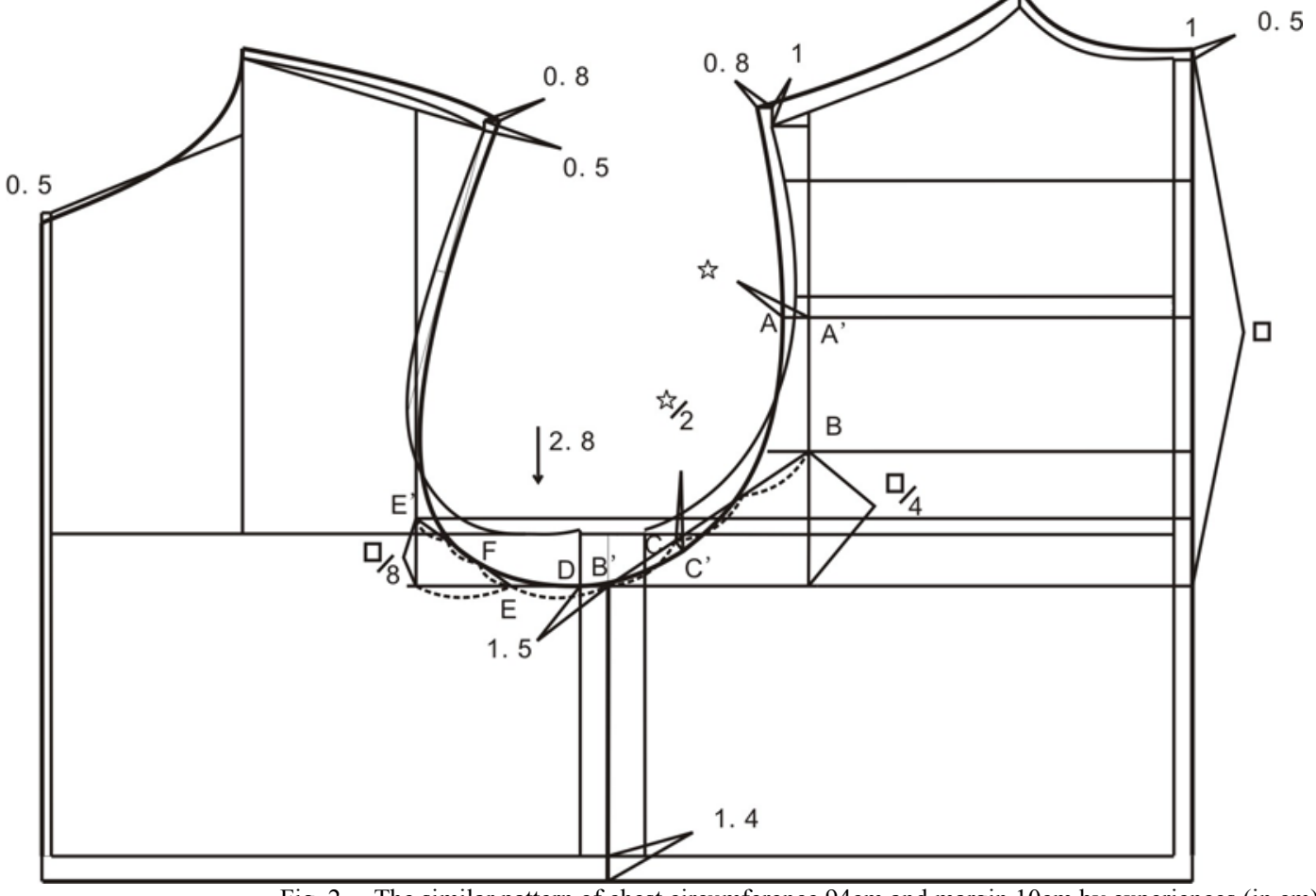

Fig. 2. The similar pattern of chest circumference $94 \mathrm{~cm}$ and margin $10 \mathrm{~cm}$ by experiences (in $\mathrm{cm}$ )

\section{The experimental analysis to determine the armhole curve of similar pattern for margin}

From the analysis of the completion of basic sub-pattern, it can be seen that the armhole curves are mostly done by experience, with uncertainty, so we should try to find a method to determine the tracing points of armhole curve according to the objective laws of armhole model. (1) the shoulder point is clear after back shoulder line elevates and shoulder stretches, which is appointed as the first tracing point . (2) according to the similar principle of similar pattern for margin, the part at about 2/ 3 over armhole curve keeps parallel to the armhole curve of original basic pattern. It is given that $1 / 2$ bisector of new armhole curve intersects with the new armhole curve at Point A, and with back width line at Point A '. (3) According to the method to determine the prototype tracing point, we find the $1 / 4$ bisector of new armhole curve intersecting with back stretching line at Point $\mathrm{B}$, the new side seam intersecting with the new armhole curve at Point B ' , connect Point B with Point $\mathrm{B}$ ', and find the point $1 / 3$ of the lower of line segment $\mathrm{BB}^{\prime}$ at Point $\mathrm{C}$, to make the through point $\mathrm{C}$ to do the line vertical to segment $\mathrm{BB}$ ' through Point $\mathrm{C}$ to intersect with the new armhole curve at Point $\mathrm{C}^{\prime}$. After analysis, the line segment $\mathrm{CC}$ ' is approximately equal to the line $1 / 2$ of $\mathrm{AA}^{\prime}$, which provide a reference for us go determine Point $\mathrm{C}^{\prime}$, but such proportional relations may vary with the change of the chest circumference and margin, so it still requires the following experiments are performed to verify its rationality. (4) By experiments, we can see the fourth tracing point of armhole curve is just at the crossing point of the former seam of fore piece and the new depth line of armhole, defined as Point D. (5) the fifth tracing point of armhole curve is determined by taking the point at $1 / 2$ of distance between new side seam and chest breadth line as Point E, with $1 / 8$ bisector of new depth line of armhole crossing with chest breadth line at Point E ', connecting Point E to Point E', and taking the point at $1 / 3$ of the lower of the connection line as the fifth tracing point of armhole curve, defined as Point F. ( 6 ) the shoulder point after fore shoulder line elevating and shoulder stretching is appointed as the sixth tracing point of armhole curve.

So far, the tracing point got from the analysis of armhole curve of similar pattern for margin by experiences has been completed, and then is it rational for these tracing points to vary with the change of chest circumference and margin? Thus, by the methods to study armhole curve of similar pattern for margin, shown in Fig.1, we will complete the following experiment to verify its reasonableness (Fig. 3, Fig. 4). 


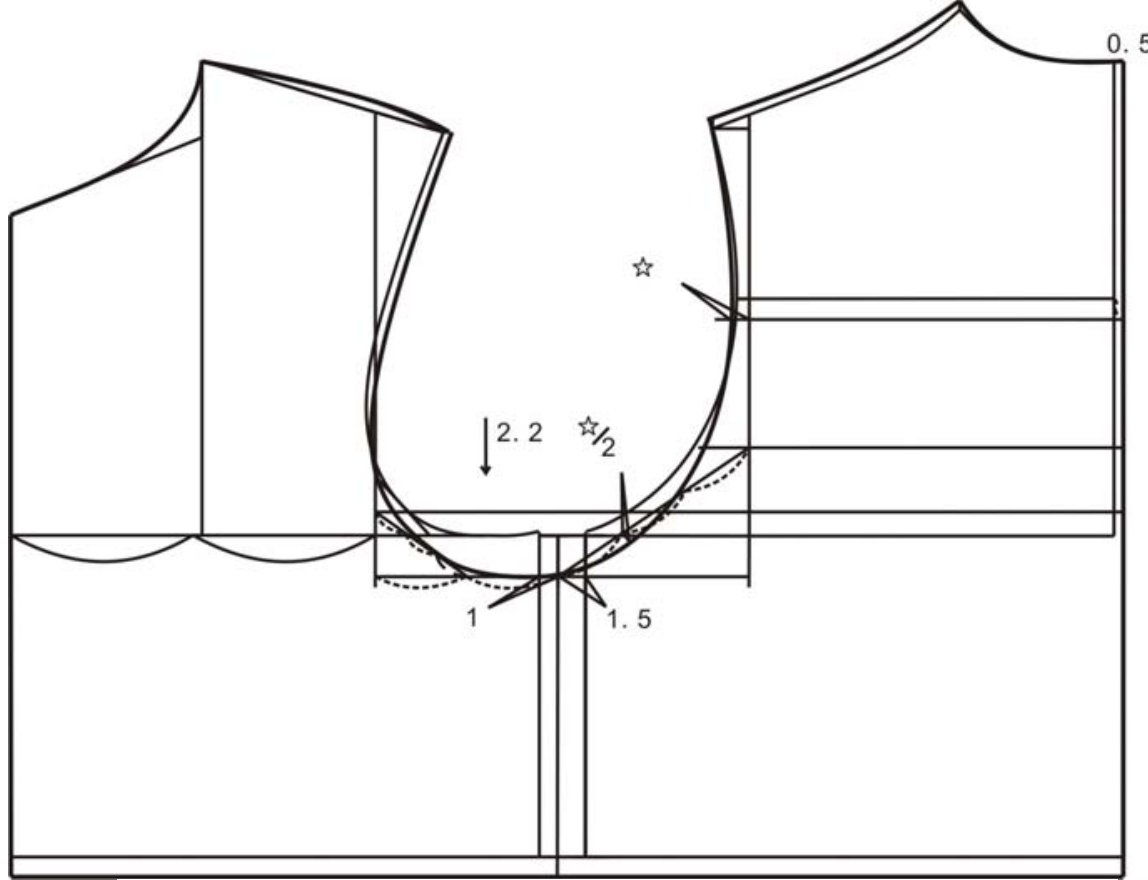

Similar pattern of chest circumference 94 and margin 6 for margin structure

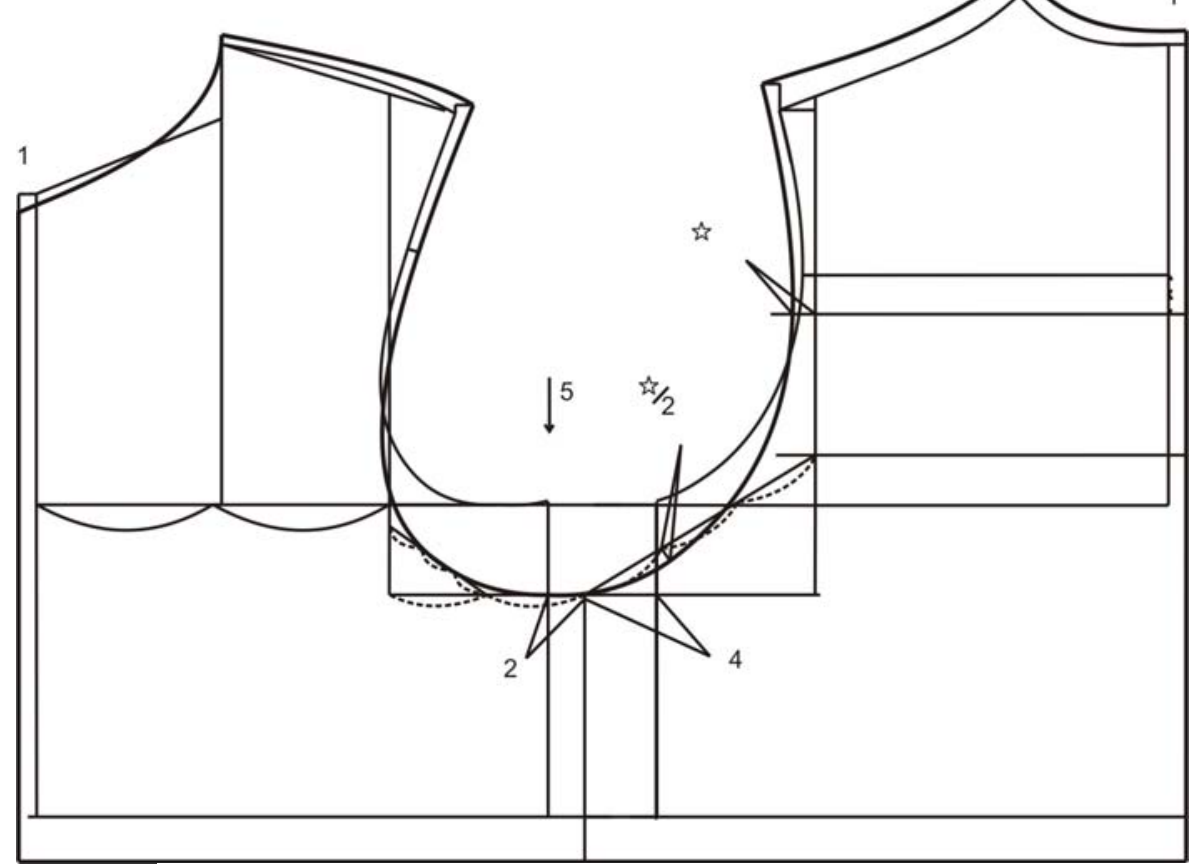

Similar pattern of chest circumference 94 and margin 16 for margin structure

Fig. 3. The experiment to determine the armhole curve of similar pattern with the same specifications but different margins 


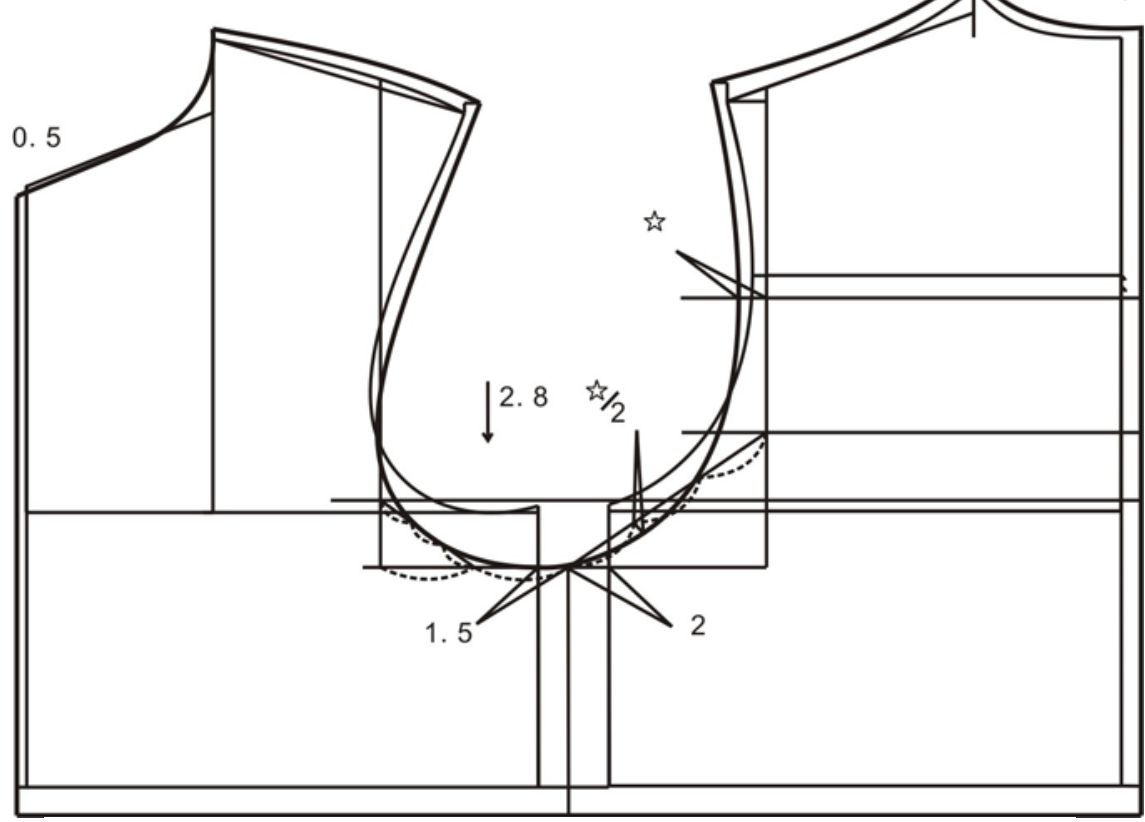

Similar pattern of chest circumference 84 and margin 10 for margin structure

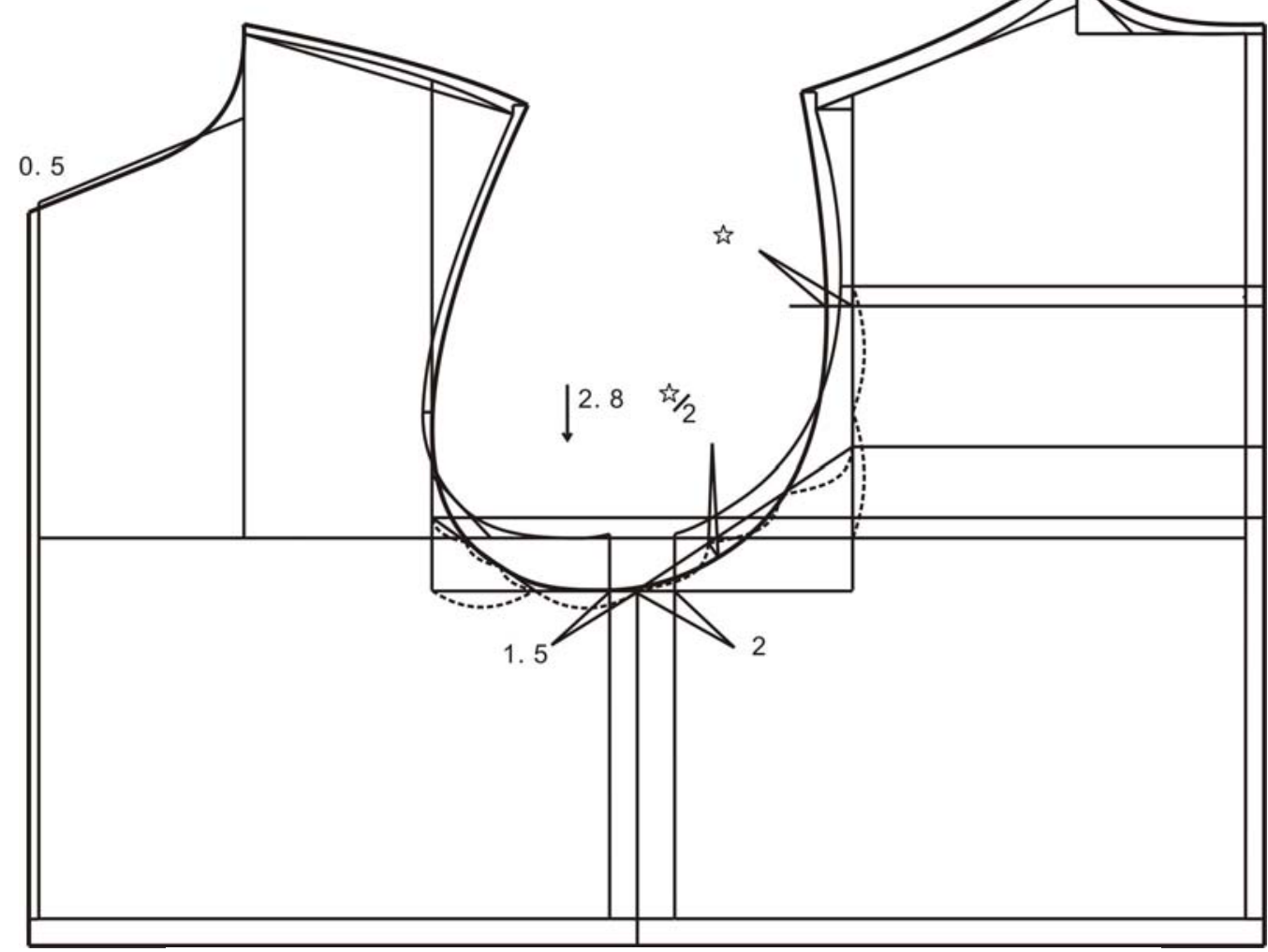

Similar pattern of chest circumference 104 and margin 10 for margin structure

Fig. 4. The experiment to determine the armhole curve of similar pattern with different specifications but the same margin

D. The experimental results to determine armhole curve of similar pattern for margin

After the verification by the above four experiments (Fig. 3,
Fig. 4), we can see that the armhole curve completed according to the six tracing points is in line with the principles of comparability for margin of similar patter, which ensures that there is no change in quality but in quantity on the base of 
former basic pattern. From drawing practices, armhole curve is smooth and elastic, in line with people's body structure and costumes model beauty, and it has strong practicality.

The line segment $\mathrm{AA}^{\prime}{ }^{\prime}$ is indicated with the symbol $\boldsymbol{t}^{2}$, and the ratio between line segment $\mathrm{AA}^{\prime}$ ' and line segment $\mathrm{CC}^{\prime}$ is CC' , approximately equal to $i s / 2$ (Table 1 , Table 2 ). The determination of the ratio provides a reliable basis for the determination of armhole curve of similar pattern for margin.

TABLE 1. COMPARISON UNDER THE SAME CHEST CIRCUMFERENCE (94) BUT DIFFERENT MARGINS

Unit: $\mathrm{cm}$

\begin{tabular}{l|cl}
\multicolumn{2}{c}{} & \multicolumn{2}{c}{ Unit: $\mathbf{c m}$} \\
\hline Margin & $\mathbf{A A}^{\prime}(\boldsymbol{\zeta})$ & $\mathbf{C C}^{\prime}$ \\
\hline 6 & 1 & 0.5 \\
10 & 1.4 & 0.65 \\
16 & 1.4 & 0.7 \\
& & \\
\hline
\end{tabular}

TABLE 2. COMPARISON UNDER THE SAME MARGIN (10) BUT DIFFERENT CHEST CIRCUMFERENCES

Unit: $\mathrm{cm}$

\begin{tabular}{l|cl}
\hline Margin & $\mathbf{A A}^{\prime}(\boldsymbol{\jmath})$ & $\mathbf{C C}^{\prime}{ }^{\prime}$ \\
\hline 84 & 1.3 & 0.65 \\
94 & 1.4 & 0.7 \\
104 & 1.2 & 0.6 \\
& & \\
\hline
\end{tabular}

\section{THE EXPERIMENT OF SLEEVES ARRANGEMENT FOR MARGIN} OF SIMILAR PATTERN

\section{A. The experimental method of sleeves arrangement for margin of similar pattern}

After completion of armhole curve of similar pattern for margin, the sleeves arrangement is also completed by determining the tracing points of sleeve cap curve through the proportional relations. First complete the drawing of similar sleeve pattern for margin on the base of completed similar jacket pattern according to the drawing method of two-piece sleeves of men's clothing; second, analyze the methods to determine the tracing points of sleeve cap curve; finally, carry out verification of reasonableness to determine the tracing points of sleeve cap curve (Fig. 1) by the way of taking chest circumference $94 \mathrm{~cm}$ and margin $10 \mathrm{~cm}$ as the center and radiating around.

\section{B. The experimental procedure of sleeves arrangement of similar pattern for margin structure}

First, complete the basic framework according to the methods of sleeves arrangement of similar pattern of men's clothing for margin (Fig. 5): (1) measure $3 \mathrm{~cm}$ down from the back shoulder point of basic pattern along the armhole curve and take it as the top line of sleeve cap (M). (2) from the point of bisection of distance between $1 / 2$ point of armhole depth line of basic pattern and that of basic sub-pattern after margin completion, draw a parallel line as the second auxiliary line to draw sleeve cap (L). (3) The armhole depth line of basic sub-pattern after margin completion is taken as the bottom line of sleeve $(\mathrm{N})$.
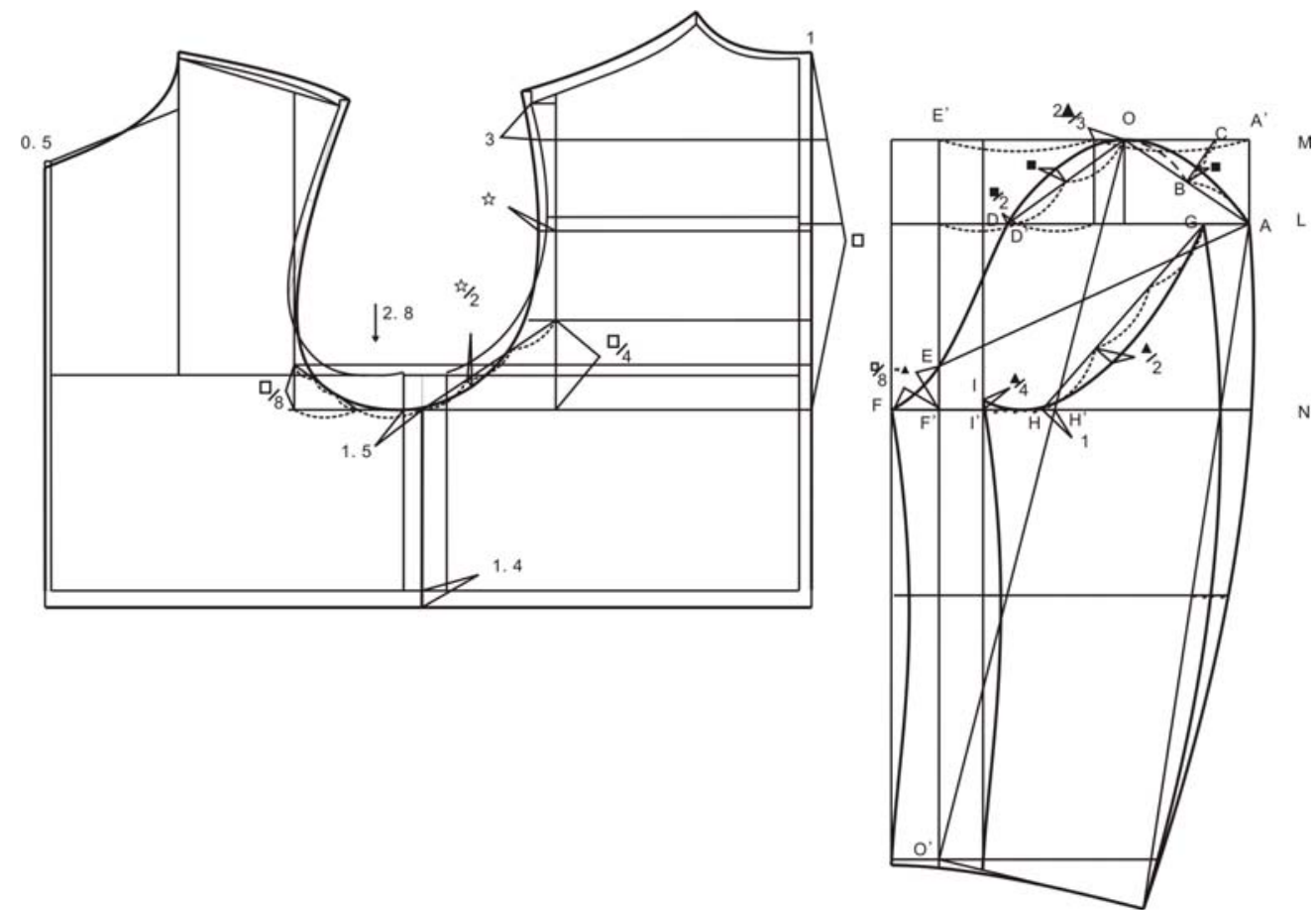

Fig. 5. The sleeve pattern of similar shape of chest circumference $94 \mathrm{~cm}$ and margin $10 \mathrm{~cm}$ for margin drawn by experiences

Next, determine the top sleeve crown curve and under sleeve crown curve: (1) measure off one eighth of the new armhole depth line along upward direction from the sleeve baseline, namely $\square / 8=\boldsymbol{\Delta}$ which is defined as Point E, the upward inclined vector $\mathrm{AH} / 2-4$ through Point $\mathrm{E}$ intersects with $\mathrm{L}$ at Point A, through Point E and Point A, respectively draw 
the vertical lines of sleeve crown top-line (M), intersecting the sleeve crown top-line at Point $\mathrm{E}^{\prime}$ and Point $\mathrm{A}^{\prime}$, take the midpoint of Segment E'A', shift the midpoint to the right by $2 \Delta / 3$ and set as sleeve vertex $\mathrm{O}$, and the downward inclined vector sleeve length through Point $\mathrm{O}$ intersects with the extension line of EE' at Point $\mathrm{O}^{\prime}$; (2) before the determination of the fourth tracing point, first determine the position of the fifth tracing point of top sleeve crown, according to experience, shift Point $\mathrm{D}^{\prime}$ to the right by $0.7 \mathrm{~cm}$ and set as Point $\mathrm{D}$, and the length of Segment DD' is about $\mathbf{a} / 2$; (3) the sleeve baseline (N) intersects with the extension line of EE' at Point $\mathrm{F}^{\prime}$, measure off a length of $\square / 8=\boldsymbol{\Delta}$ towards the left and set as Point F; (4) connect Point A, Point O, Point D, Point E and Point F in sequence and complete the top sleeve crown curve; (5) on the Line L, measure off a length of $\square / 8=\boldsymbol{\Delta}$ towards the left of Point A and set as Point G; (6) Segment OO' intersects with the sleeve baseline $(\mathrm{N})$ at Point $\mathrm{H}^{\prime}$, through Point $\mathrm{H}^{\prime}$ measure off $1 \mathrm{~cm}$ towards the left and set as Point $\mathrm{H}$; (7) through Point F measure off a length of $\square / 8=\boldsymbol{\Delta}$ towards the right and set as Point I', and through I' measure off $0.8 \mathrm{~cm}$ along the straight-up direction and set as Point I; (8) connect Point G, Point $\mathrm{H}$ and Point $\mathrm{I}$ in sequence and complete the under sleeve crown curve; (9) complete the side seams of top and under sleeves and finally finish the sleeve pattern.

\section{Experimental analysis of sleeves arrangement of similar pattern margin}

The methods to determine the tracing points of sleeve crown curve in accordance with objective laws based on the analysis on the basic sub-pattern of completed sleeves of similar pattern margin:
First, determine the top sleeve crown curve (Fig. 5): (1) connect the top sleeve crown vertex $\mathrm{O}$ and Point $\mathrm{A}$, through the midpoint B of Segment OA, draw its vertical line crossed at Point C, equally divide Segment BC into three parts and take its one third as curve convex amount which is marked as -; (2) on the Line L, shift the point at one fourth of Segment E'A' towards the left by $\mathbf{m} / 2$ and set as the fifth tracing point of top sleeve crown, marking it as Point D; (3) determine the outward convex of the midpoint of Segment OD as the fourth tracing point of top sleeve crown.

Next, determine the under sleeve crown curve: (1) equally divide Segment GH into three parts and take its one third as curve convex amount which is marked as $\boldsymbol{\Delta} / 2$; (2) measure off $\Delta / 4$ towards the upward from the intersection of the inside seam of under sleeve intersects and the sleeve baseline $(\mathrm{N})$, take it as the end point of under sleeve crown curve and complete the under sleeve crown curve.

At this point, the tracing points have been achieved through the analysis on the sleeve crown curve of similar pattern margin completed in accordance with experience. Via measurement, the length of sleeve crown curve is $67.7 \mathrm{~cm}$, the length of armhole curve $\mathrm{AH}$ is $62.5 \mathrm{~cm}$, and the difference between them is $5.2 \mathrm{~cm}$, which is within the normal range. Then, are these tracing points still reasonable along with the changes in chest circumference and margin? To understand this, we will complete the following reasonability-verifying experiment (Fig. 6 and Fig. 7) in accordance with the methods for the study on the armhole curve of similar pattern margin as shown in Fig. 1.
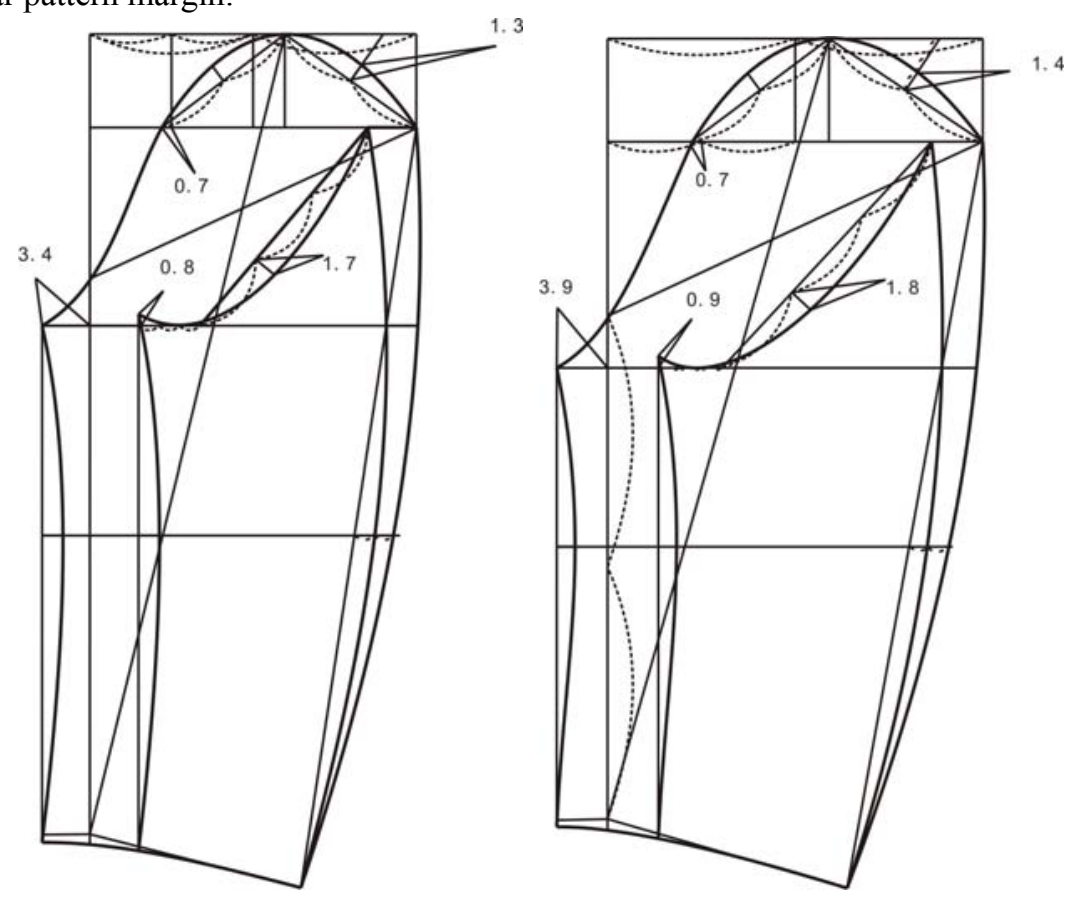

Sleeves arrangement with chest circumference Sleeves arrangement with chest circumference $94 \mathrm{~cm}$ and $94 \mathrm{~cm}$ and margin $6 \mathrm{~cm}$ margin $16 \mathrm{~cm}$

Fig. 6. Sleeves arrangement of similar pattern with same specification (chest circumference $94 \mathrm{~cm}$ ) but different margins 


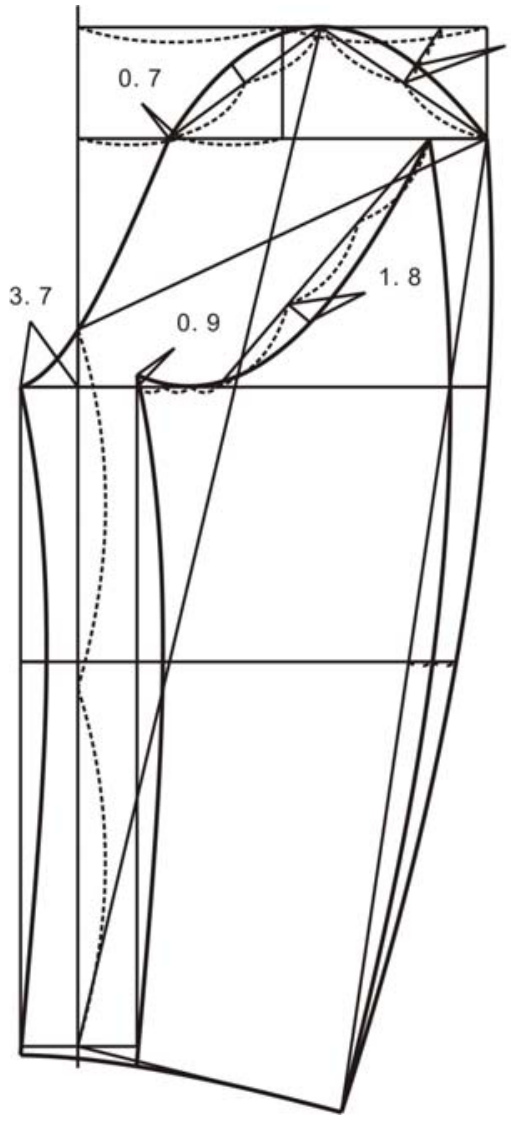

Sleeves arrangement with chest circumference $84 \mathrm{~cm}$ and margin $10 \mathrm{~cm}$

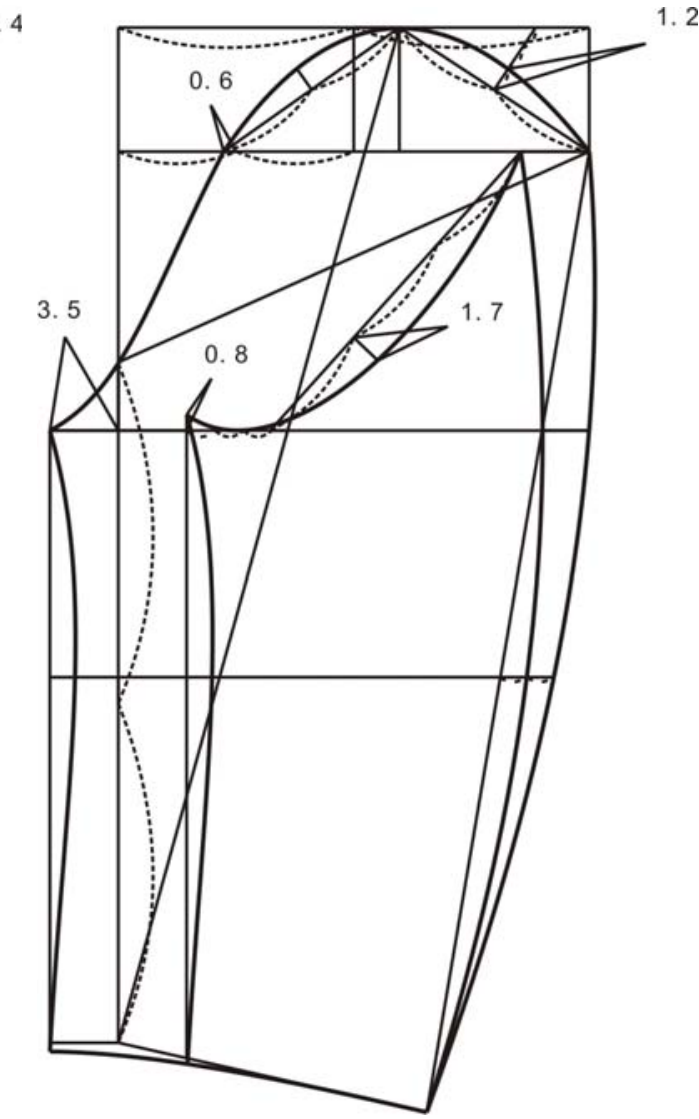

Sleeves arrangement with chest circumference $104 \mathrm{~cm}$ and margin $10 \mathrm{~cm}$

Fig.7. Sleeves arrangement of similar pattern with different specifications (chest circumference $94 \mathrm{~cm}$ ) but the same margin

\section{The experimental results of sleeves arrangement of similar pattern margin}

In the practice of drawing patterns, it's better to use scaling relation rather than constant so as to make the pattern drawing more convenient and easier to memorize. Experimental results show that it's more feasible and convenient to take one third of the Segment BC vertical to the Segment OA through midpoint on top sleeve crown as convex amount, which is also applicable to the convex amount of Segment OD.

The fifth tracing point $\mathrm{D}$ on top sleeve crown is determined by measuring off $\boldsymbol{\omega} / 2$ towards the left from Point $\mathrm{D}^{\prime}$, which conforms to the existing empirical value $0.7 \mathrm{~cm}$ and is reasonable (Table 3 and Table 4).

TABLE 3 COMPARISON UNDER THE SAME CHEST CIRCUMFERENCE (94) BUT

\begin{tabular}{|c|c|c|}
\hline Margin & $\mathrm{B} \mathrm{C} / 3(\square)$ & $\mathrm{D} \mathrm{D}^{\prime}$ \\
\hline 6 & 1.4 & 0.7 \\
\hline 10 & 1.3 & 0.65 \\
\hline 16 & 1.3 & 0.7 \\
\hline
\end{tabular}

TABLE 4 COMPARISON UNDER THE SAME MARGIN (10) BUT DIFFERENT CHEST CIRCUMFERENCES Unit: $\mathrm{cm}$

\begin{tabular}{c|cl}
\hline $\begin{array}{c}\text { Chest } \\
\text { circumference }\end{array}$ & B C / 3 ( $)$ & $\mathrm{D} \mathrm{D} \mathrm{D}^{\prime}$ \\
\hline 84 & 1.4 & 0.7 \\
94 & 1.3 & 0.65 \\
104 & 1.2 & 0.6 \\
\hline
\end{tabular}

Through the above experiment, we can verify the matching reasonability of sleeve pattern and coat pattern after similar pattern margin via the difference between armhole curve (AH) and sleeve crown curve (Table 5 and Table 6). It can be learned from Tables 5 and 6 that: the length difference between armhole curve and sleeve crown curve is within the reasonable range (about $5 \mathrm{~cm}$ ); the smaller the value is, the simpler the process will be, otherwise, the making process will be very complicated but the stereoscopic effect of sleeves will be better. 
TABLE 5 STATISTICS OF THE DIFFERENCE BETWEEN ARMHOLE CURVE (AH) AND SLEEVE CROWN CURVE WITH THE SAME CHEST CIRCUMFERENCE (94) BUT DIFFERENT MARGINS

Unit: (cm)

\begin{tabular}{c|ccc}
\hline Margin & $\begin{array}{c}\text { Armhole curve } \\
\text { (AH) }\end{array}$ & $\begin{array}{c}\text { Sleeve crown } \\
\text { curve }\end{array}$ & Difference \\
\hline 6 & 60 & 64.9 & 4.9 \\
10 & 62.5 & 67.7 & 5.2 \\
16 & 69.5 & 75 & 5.5 \\
\hline
\end{tabular}

TABLE 6 STATISTICS OF THE DIFFERENCE BETWEEN ARMHOLE CURVE (AH) AND SLEEVE CROWN CURVE WITH DIFFERENT CHEST CIRCUMFERENCES AND THE SAME MARGIN (10)

Unit: (cm)

\begin{tabular}{l|lll}
\hline $\begin{array}{c}\text { Chest } \\
\text { circumference }\end{array}$ & $\begin{array}{c}\text { Armhole curve } \\
\text { (AH) }\end{array}$ & $\begin{array}{c}\text { Sleeve crown } \\
\text { curve }\end{array}$ & Difference \\
\hline 84 & 59.7 & 63.5 & 3.8 \\
94 & 62.5 & 67.7 & 5.2 \\
104 & 66.9 & 71.5 & 4.6 \\
\hline
\end{tabular}

\section{CONCLUSIONS}

By experiments, we have got the proportional relations to determine the tracing points of armhole curve and sleeve cap curve of similar pattern for margin, and verified its reasonableness with the maximum and minimum limit values of chest circumference and margin.

In this paper, we try to use the ratio rather than the constant to determine the tracing points of curve, and it is possible that in the determination of tracing points, as long as a parameter is changed, all the tracing points of the entire pattern will be changed. That is, if the chest circumference is different, all of other parameters will be different. Thus it solves the problems of pattern deformation in drawing the garment patterns of different models due to one fixed value or experience pattern used separately, and it also provides an expert knowledge platform for the development of PDS intelligent systems of computer in the future.

\section{REFERENCES}

[1] Liu Ruipu. Clothing Pattern Design Principle and Application. Male's Article[M]. Beijing: China Textile Press, 2008.10

[2] Liu Ruipu. Clothing Pattern Design Principle and Application. Female's Article[M]. Beijing: China Textile Press, 2008.

[3] Zhang Ling, Zhang Hui. Clothing CAD Plate Type Design[M]. Beijing: China Textile Press, 2002.

[4] Zhang Ning, The Research of Design and Method of Series of Male's Clothing Pattern [D]. Master degree thesis of Beijing Institute of Fashion Technology, 2009.

[5]. Wang Junxia, The Research of Design and Method of Series of Female's Clothing Pattern [D]. Master degree thesis of Beijing Institute of Fashion Technology, 2009.

[6]. Zhang Jinmei, Liu Ruipu. The Reasonablenessof AH / 3 as Standard Sleeve Height [J]. Journal of Tianjin University of Technology, 2004 (10) 